\title{
EL YACIMIENTO DE "EL ACEGUCHAL" (CARMONA, SEVILLA): UN ANÁLISIS DE LAS ESTRUCTURAS CALCOLIITICAS A TRAVÉS DE LOS ESCRITOS INÉDITOS DE J. BONSOR E HISTORIOGRAFÍA
}

\author{
"EL ACEBUCHAL" (CARMONA, SEVILLA). A ANALYSIS OF THE COPPER \\ AGE STRUCTURES THROUGH UNPUBLISHED DOCUMENTS FROM \\ THE BONSOR FUNDS AND HISTORIOGRAPHY DATA
}

\author{
por \\ MARÍA LAZARICH GONZÁLEZ \\ INMACULADA LADRÓN DE GUEVARA \\ MERCEDES RODRÍGUEZ DE ZUOLAGA \\ MILAGROSA SÁNCHEZ ANDREU
}

RESUMEN Los hallazgos campaniformes procedentes del yacimiento de El Acebuchal (Carmona, Sevilla) han sido reproducidos y estudiados en numerosos trabajos desde que Bonsor publicara su artículo "Les Colonies agricoles pré-romaines de la vallée du Bétis". Sin embargo, la mayor parte de las estructuras y productos arqueológicos correspondientes a este horizonte fueron localizados en las excavaciones de Bonsor entre 1908 y 1911, trabajos que nunca llegaron a publicarse. Por ello el objetivo fundamental del presente trabajo es dar a conocer esta documentación y con ello eliminar cierto confusionismo existente en la historiografía posterior a Bonsor sobre este yacimiento.

ABSTRACT The Bell Beaker findings from the beds of El Acebuchal have been reproduced and studied in many essays since Bonsor published his paper "Les Colonies agricoles pré-romaines de la vallée du Bétis". However, most of the archeological structures and products related to this culture had been detected in his excavations in 1908 and 1911, the results of which were never printed. For this reason, the main aim of this paper is to reveal these data and, in this way, to put an end to some disorder found in the following refeferences to Bonsor about this deposit. 


\section{INTRODUCCIÓN}

El yacimiento de El Acebuchal, situado en uno de los rebordes montañosos o "alcores" que dan hacia la Vega de Carmona, se introduce en la historiografía arqueológica en 1885, cuando un grupo de miembros de la recién creada Sociedad Arqueológica de Carmona visita el lugar reconociendo restos que atribuyen a época romana (Bonsor 1885). Posteriormente, los hallazgos debieron de seguir produciéndose, pues existe gran interés en realizar excavaciones '. Así en 1891 J. Peláez y Barrón llevará a cabo los primeros trabajos, localizando varios túmulos con sepulturas de época orientalizante. Sobre estas primeras excavaciones tenemos noticias recogidas por diferentes investigadores (Cabrera 1893; Fernández Casanova 1893; Candau 1894; Cañal 1894; Bonsor 1899). Todos ellos se hacen eco de la presencia de fragmentos cerámicos decorados e industria lítica en la tierra que forman los túmulos, que son considerados vestigios del poblamiento más antiguo en el lugar. De todas formas, los primeros hallazgos de estructuras calcolíticas no se producirían hasta 1896, año en que J. Bonsor se hace cargo de las excavaciones. Todo lo acaecido en esta primera campaña quedará recogido en su obra "Les Colonies agricoles pré-romaines de la vallée du Bétis" (Bonsor 1899). Sin embargo, los trabajos realizados desde 1908 a 1911, como algunas exploraciones de R. Pérez ${ }^{2}$, no llegaron nunca a publicarse, salvo algunas breves referencias en sus artículos de 1924 (?) y 1927 (Bonsor).

Con esta parquedad de datos se darán a conocer las magníficas vasijas campaniformes, localizadas en las excavaciones posteriores a la publicación de 1899 y, sobre todo, el lote vendido a la Hispanic Society (Castillo 1922, 1928 y 1943; Bosch-Gimpera 1940 y 1962; Frothingan 1953 Harrison y otros, 1976; Harrison 1977 y 1980, entre otros). Algunos investigadores no hacen referencia a las estructuras en que se hallaron tales cerámicas; otros se limitan a seguir el relato de Bonsor en "Les Colonies..." y citar como lugar de localización los "pozos M" y, por último, los más atrevidos, nos hablan de la existencia de elementos de hábitat y/ o de sepulturas.

Ante tal desinformación, consideramos oportuno acudir directamente a los diarios y anotaciones manuscritas de Bonsor para esclarecer, en la medida de lo posible, el contexto en que aparecían las vasijas campaniformes. Con este objetivo realizamos diversas visitas al Archivo General de Andalucía, donde se encuentran depositados tales documentos ${ }^{3}$. Allí consultamos los Legajos 4, P. 3: Fouilles archéologiques des Alcores 1908-1912 (manuscrito); Legajo 12, P. 1: Acebuchal 1896 (manuscrito en francés); Legajo 15, P. 4: Cuaderno de apuntes y dibujos de arqueología (manuscrito en inglés, francés y español) y P. 6: Álbum archéologique des Alcores; Legajo 16, P. 2 y 3: Traducción de los trabajos de Bonsor sobre el Acebuchal (manuscrito anónimo) ${ }^{4}$; y Legajo 18, P. 9: Diario de notas arqueológicas, 1903-1905, 1907 y 1909-1910 (manuscrito en francés) (Cruces 1991).

\footnotetext{
1. Sabemos por el propio Bonsor de su intención de realizar excavaciones en el lugar junto con J. Richard, miembro de La Societé de Antiquaires de L' Ouest; pero aprovechando su ausencia J. Peláez se le adelantó, hecho que causó gran malestar a Bonsor (1899: 24).

2. Va a ser el principal excavador de J. Bonsor durante varios años, no sólo en El Acebuchal sino en todo el Alcor. Es quien descubriría la mayor parte de las vasijas campaniformes completas aparecidas en el yacimiento y que más tarde venderá a Bonsor.

3. Queremos agradecer a todo el personal del Archivo General de Andalucía la ayuda prestada, y muy en particular a Ana Melero Sánchez, del Dpto. de Conservación e Investigación.

4. Este legajo, aunque la mayor parte de la documentación es anónima, pertenece al borrador de las traducciones de los diarios de Bonsor por su sobrina Dña. María Peñalver Simó para la redacción de su tesis de licenciatura que, permanece inédita.
} 


\section{LOS TRABAJOS DE J. PELÁEZ Y BARRÓN}

Estos primeros trabajos, realizados desde 1891 a 1893, no fueron muy satisfactorios. Bonsor se queja del poco rigor llevado a cabo por Peláez, quien se limitó a extraer los objetos de los túmulos sin anotar el lugar exacto de procedencia y, luego en su museo, los clasificó por la materia prima en que estaban realizados (Bonsor 1899: 24). Ello llevó a los investigadores encargados de transmitirnos estos hallazgos a tal confusión que algunos consideran los instrumentos de sílex hallados en el yacimiento como parte de los ajuares de las sepulturas orientalizantes (Candau 1894: 49-53; Cañal 1894: 64); otros comentan que aparecieron mezclados en la tierra que contenía los restos humanos (Cabrera 1893: 106; Fernández Casanova 1893: 310 y 313). Lo mismo ocurre con la cerámica; todos hacen referencia a la presencia de fragmentos cerámicos decorados con técnicas de incisión e/o impresión, pero ninguno sabe con certeza el lugar exacto de procedencia (Cabrera 1893: 107, lám. 3a: 6-8; Fernández Casanova 1893: láms. III-IV). Candau cita una treintena de fragmentos de los cuales sólo publica el dibujo de once (Candau 1894: figs. 29-39). También se realiza algún que otro comentario respecto a las formas a la que corresponderían tales fragmentos, entre las que destacaban los vasos y platos (Cabrera 1893: 107; Cañal 1894: 87).

Bonsor, al hacer referencia a estos hallazgos, nos trasmite una información más clara y precisa pues, como ya comentamos anteriormente, contó con un informador de primera mano, R. Pérez Barrera, que fue uno de los obreros que participaron en las exploraciones de Peláez, y que se convertirá más tarde en el "excavador" por excelencia de las intervenciones arqueológicas de Bonsor ${ }^{5}$. Así, nos narra que los instrumentos de sílex sólo aparecieron en la tierra que cubría la sepultura del túmulo L, y los considera correspondientes a una etapa anterior a la construcción de éste (Bonsor 1899: 23); hecho que debió de provocar la destrucción de un estrato con restos arqueológicos, existente en un nivel inmediatamente inferior a la base del túmulo.

\section{LOS PRIMEROS TRABAJOS DE BONSOR EN EL ACEBUCHAL: LAS EXCAVACIONES DE 1896}

La mayor parte de la información sobre las primeras excavaciones llevadas a cabo por Bonsor está recogida en su artículo "Les colonies agricoles pré-romaines de la vallée du Bétis" (1899), por lo que sólo insistiremos en los datos que no se mencionan en esta obra, o que aparecen de forma distinta en sus anotaciones inéditas.

La documentación conservada en el Archivo General de Andalucía sobre los trabajos de 1896 es bastante escasa, pues se reduce a diecisiete pequeñas hojas sueltas (Leg. 12, P. 1) ${ }^{6}$. No sabemos si éstas son las únicas anotaciones que Bonsor realizó, o como cree E. Cruces faltan algunos diarios de los que desconocemos su paradero actual (Cruces 1991: 10).

A toda esta documentación sólo nos queda añadir el artículo publicado en 1897 (Bonsor 1897).

5. Como el propio Bonsor lo denomina en algunas de sus cartas personales (Archivo General de Andalucía, Legado Bonsor Leg. 13. P. 2).

6. Estas hojas no suelen estar fechadas, por lo que su ordenación se ha realizado en función de la información que contienen (E. Cruces 1991). 
Respecto a la documentación inédita, de las diecisiete hojas sueltas las que llevan los números 13 y 14 contienen datos de las excavaciones de Peláez, que casi con toda seguridad le fueron trasmitidos por R. Pérez (Bonsor 1899: 20-30; Archivo General de Andalucía, Legado Bonsor: Leg. 12, P. 1, Hojas 13 y 14).

Hacia primeros de Marzo de 1896 Bonsor comienza la excavación del denominado túmulo "A", que no había sido explorado por Peláez; bajo él halla cuatro estructuras siliformes, de las cuales dos contenían restos humanos (Bonsor 1899: 31). Entre sus escritos personales existen dos hojas sueltas dedicadas a la descripción de la construcción del túmulo y del interior de los silos (fig. 1: a). Sobre todo se detiene en el silo "B", que corresponde al denominado "C" en su obra de 1899 (Archivo General de Andalucía, Legado Bonsor: Leg. 12, P. 1, Hojas: 4 y 5). Analizando el texto que contienen estas hojas hemos podido comprobar que no hay referencia alguna a hallazgos de cerámica de tipo campaniforme, como tampoco la hay en su artículo "Les colonies agricoles...", aunque algunos autores así lo han afirmado (Harrison y otros 1976). Sí nos narra la presencia de elementos que relaciona con un nivel de hábitat inmediato a estos silos con sepulturas: piedras planas de molino, moletas, piedras quemadas de hogares; así como la existencia de depresiones naturales en la roca que suelen contener los mismos objetos (Archivo General de Andalucía, Legado Bonsor: Leg. 12. P. 1, Hoja 4).

Después Bonsor se dirige hacia un área situada más al oeste del yacimiento, cercana al conocido como "grupo central" (túmulos "H", "I" y "J") (lám. I y fig. 1), donde comienza a localizar los primeros "pozos M" que en un principio denomina silos. Es aquí cuando, por primera vez, halla fragmentos de cerámica campaniforme, que designa como de "decoración puntillada" (Ibidem Leg. 12, P. 1, Hojas 1 y 2).

Al parecer, excavando una de las sepulturas de los denominados "lapidados" de la necrópolis orientalizante (fig. 1: b), Bonsor pudo observar que en la tierra de los alrededores aparecían numerosos vestigios de cabañas u hogares. Había piedras quemadas, huesos de animales, fragmentos de cerámica lisa y decorada con "puntillado geométrico", hojas de sílex, y punzones de hueso y de cobre; igualmente estos restos se hallaban cubiertos por piedras (Bonsor, 1899: 88). Debajo de este nivel de detrito localiza varios pozos. Aunque llega a descubrir 22 pozos sólo describe de forma detallada en sus notas siete de estas estructuras, que quizás fueron las únicas excavadas en su presencia. En las primeras anotaciones cita el hallazgo de tres "silos" y los enumera (Archivo General de Andalucía, Legado Bonsor: Leg. 12, P. 1, Hoja 2) (fig. 1: a):

Silo 1.- Situado entre los túmulos de incineración. En su superficie se hallaron 2 punzones de hueso, restos de animales y fragmentos de cerámica decorada. A algo más de $50 \mathrm{~cm}$ de profundidad una gran mandíbula de animal, y a $80 \mathrm{~cm}$. gran cantidad de huesos de animales, y fragmentos de cerámica oscura, algunos con decoración puntillada, así como grandes fragmentos de cerámica lisa bruñida, todos fabricadas a mano.

Silo 2.- Proporcionó una pátera entera, un punzón de hueso, el asa y parte de la base de un vaso, numerosos fragmentos decorados, huesos de animales quemados, y en el fondo tres pesas de telar fragmentadas ${ }^{7}$.

Silo 3.- En su interior se localizó un punzón de hueso, numerosos fragmentos de cerámica decorada y huesos de animales quemados.

Luego hace referencia a dos pozos más que no enumera, en cuyos fondos aparecieron una lámina de sílex en uno y el hueso interno de la pezuña de un cérvido en el otro.

7. Consisten en piezas de arcilla con forma rectangular y los extremos redondeados, con dos perforaciones en cada uno de ellos. 
En la misma hoja nos describe otro grupo de pozos a los que Bonsor los designa con las letras A, B, C y D (fig. 1: a). Los tres primeros contenían tierra vegetal oscura, mientras que el pozo D aparecía lleno de tierra de color amarillo. Todos ellos proporcionaron fragmentos de vasijas de tipo campaniforme (Ibidem, Leg. 12, P. 1, Hoja 2).

La estructura de estos pozos suele presentar una profundidad entre 2, $20 \mathrm{~m} \mathrm{y} 1,30 \mathrm{~m}$., un diámetro en la parte superior que no suele superar $1 \mathrm{~m}$., mientras que a medida que se acerca al fondo aumenta levemente éste, llegando a los 1,20 m.; estructura que se aprecia perfectamente en la sección del dibujo que realiza de uno de ellos (fig 2: a), donde podemos observar la existencia de una oquedad labrada, cercana a la boca que recorre todo su perímetro, y que quizás pudo haber servido para sujetar una tapadera o cubierta (Ibidem, Hoja 2). En el interior de estos pozos, además de numerosos fragmentos campaniformes, localizó dos vasijas completas ${ }^{8}$. Generalmente contenían restos similares. Además de las cerámicas citadas, había fragmentos de cerámica lisa con tratamiento bruñido, punzones de hueso o metal ${ }^{9}$, piedras quemadas, huesos de animales, que corresponden a partes del cráneo, mandíbulas y pezuñas o falanges de cerdos o jabalíes, frecuentemente también con señales de fuego, asimismo, aunque en menor proporción, grandes huesos de caballo, bóvido y ciervo. Aparte de estos restos aparecen otros, pero siempre en reducido número, como láminas de sílex, 2 dientes de hoz, 2 "brazales de arquero", dos botones de marfil ${ }^{10}$, un "ídolo" y algunas pesas de telar con dos o cuatro orificios (Bonsor 1899: 88: figs. 119-126; Archivo General de Andalucía, Legado Bonsor: Leg. 12, P. 1, Hojas 1-2).

Existe una hoja, con fecha de Abril de 1896, en que Bonsor nos relata las exploraciones realizadas en el lugar que denomina "El gran cercado de los sacrificios" (Ibidem, Leg. 12, P. 1, Hoja 3), o "Roca de los sacrificios" como más tarde la llama en su publicación (1899: 95). Esta estructura se encuentra en El Acebuchal Bajo, en la terraza inferior que conecta ya con la Vega (lám. I). Señala la presencia de varios estratos, localizando en el nivel más profundo un plato de borde engrosado con $25 \mathrm{~cm}$. de diámetro, del que realiza un dibujo, para continuar enumerando una serie de hallazgos tales como carbón, piedras calcinadas, un núcleo, un hacha de piedra pulimentada, numerosas láminas de sílex y dos fragmentos de cerámica "pulida" y otras con decoración (Ibidem, Hoja 3). Descripción que coincide a grandes rasgos con la que, mucho más ordenada y detallada, trasmite en 1899 (Bonsor 1899: 97), aunque omite algunos hallazgos, como los fragmentos cerámicos. Por último, expone su hipótesis sobre la utilización del lugar como "pozo de sacrificio", apoyándose en la presencia de huesos de animales calcinados entre los que abundan los cérvidos, piedras quemadas, carbón, etc. (Archivo General de Andalucía, Legado Bonsor: Leg. 12. P. 1, Hoja 3).

Por último, en lo que respecta a las excavaciones de 1896, queremos hacer mención de una hoja suelta en la que Bonsor dibuja el plano de distribución de los 22 pozos (fig. 1: a), con un pie de página que dice:

"El Acebuchal estación neolítica a $3 \mathrm{Km}$ de Cármona. Grupo de fondos de cabañas y subterráneos (silos). De la última fase de la Edad de la piedra pulida apareciendo instrumentos de cobre." (Archivo General de Andalucía, Legado Bonsor: Leg. 12, P. 1, Hoja 9).

8. Corresponden a las figuras 122 y 128 de su obra "Les Colonies...". En esta primera campaña de 1896 fueron las únicas que se hallaron enteras como nos comunica en su artículo de 1897 (Bonsor 1897: 569).

9. Bonsor en sus escritos considera que estos objetos debieron de servir bien para la realización de tatuajes, o bien para sacar la médula de los huesos que aparecían en los fondos de cabaña y que mostraban señales de tal actividad.

10. Aunque recientemente se ha negado la existencia de estos botones (Uscatescu 1992: 136), Bonsor llegó a localizar dos ejemplares con perforación en "v"; noticia recogida ya en "Les colonies..." (1899: 89) y que encontramos también en sus diarios (Archivo General de Andalucía, Legado Bonsor: Leg. 12 P. 4 hoja 8). 
Aunque la hoja no está fechada nos extraña que realice tal afirmación en estos momentos (1896), pues en otros escritos atribuye estos silos y la cerámica con decoración campaniforme a época céltica (Bonsor 1897: 569), por lo que quizás corresponda a momentos posteriores ${ }^{11}$.

\section{LAS EXCAVACIONES DE BONSOR ENTRE 1908-1911}

Las excavaciones en el yacimiento durante estos años van a estar encaminadas fundamentalmente a la búsqueda del lugar o lugares donde aparecen los vasos completos de "cerámica con dibujos geométricos puntillados rellena de pasta blanca (...)", que R. Pérez le había vendido, y que procedían de la parte alta de El Acebuchal y de sus alrededores.

En el "Libro de "Compras y ventas..." (manuscrito en francés y español) de Bonsor existen una serie de compras, con fecha desde el 29 de Abril de 1905 al 12 de Junio de 1906, de vasos campaniformes ${ }^{12}$, cerámica neolítica ${ }^{13}$, objetos de metal y hachas pulimentadas halladas en El Acebuchal por R. Pérez. (Archivo General de Andalucía, Legado Bonsor: Leg. 18. P. 10). También sabemos de su interés por estas cerámicas en algunas anotaciones que realiza en su "Diario de notas arqueológicas 1903-1905, 1907 y 1909-1910" (manuscrito en francés) (Ibidem, P. 9). El 26 de Julio de 1907 lleva a cabo una excursión, acompañado por R. Pérez, al lugar donde éste halló los vasos que le había vendido; Bonsor lo relata así (fig. 2: b):

"Este lugar se encuentra a poca distancia de 'La Casilla del Cura' en dirección al cortijo de El Acebuchal (...). (Fig. 2: b). A $80 \mathrm{~cm}$ de profundidad aparecen piedras quemadas, y vestigios de cabañas primitivas, huesos de animales y bajo los fuegos, fragmentos de cerámica y de vasos enteros neolíticos con dibujos geométricos rellenos de pasta blanca. En otra parte, entre las piedras esqueletos humanos encogidos." (Archivo General de Andalucía, Legado Bonsor: Leg. 18. P. 9. pág. 39).

Este texto parece recoger una información que le da R. Pérez antes de realizar la mencionada excursión, pues a continuación Bonsor comenta que sólo ha encontrado vestigios de cabañas, tales como pavimentos de piedras y hogares, junto con numerosos restos de sílex, hachas de piedra, molinos. En la parte inferior de esta misma página existe una nota aclaratoria:

"He sabido más tarde que la mayor parte de las cerámicas eneolíticas que se han encontrado no proceden de este lugar o entorno, sino del otro lado del Puerto de El Acebuchal, al lado de los grupos de túmulos explorados por Peláez, en la parte alta de los Alcores." (Ibidem).

Como se puede apreciar es un párrafo que aporta mucha información aunque no tan clara como querríamos. Por una parte, sabemos que Bonsor quiere conocer la localización exacta de los vasos que

11. La atribución "céltica" por parte de Bonsor de esta cerámica es debida a la presencia de fragmentos en el fondo de la fosa de algunos de los "lapidados" y la mantendrá hasta principios de este siglo, hecho que hemos comprobado en su correspondencia con otros investigadores (Archivo General de Andalucía, Legado Bonsor: Leg. 13). Sin embargo, en la copia que hemos utilizado de su obra "Les Colonies..."aparece una fe de erratas impresa que dice: "Poterie celtique, lisez: Poterie néolithique" pero ignoramos cuándo se le añadió.

12. La mayoría de estos vasos completos fueron vendidos a la Hispanic Society de New York, y corresponden al segundo lote.

13. Bonsor se refiere a las cazuelas o fuentes carenadas; y deja claro en su diario que las encuentra debajo de las "neolíticas o eneolíticas con dibujos geométricos". 
le vende R. Pérez y éste es el motivo de la citada excursión. Así, nos informa de la existencia de un asentamiento en la cercanías de El Acebuchal, pero al otro lado del Puerto, en el que aparecen cabañas pavimentadas con piedras y hogares; por otra, las cabañas que esconden los vasos completos y los enterramientos, por la nota aclaratoria que se ve forzado a realizar, a través de una fuente de información desconocida por nosotros, debemos situarlos en la parte alta de El Acebuchal (fig. 1 y lám. I). Esta inexactitud en la localización de muchos de los hallazgos es algo común en los escritos de Bonsor, ya que a menudo recoge las noticias que le aportaban los obreros que trabajaban con él.

Después de esta exploración no tenemos más información hasta el viernes 28 de Febrero en que Bonsor emprende de nuevo de una forma sistemática las excavaciones. Ya comentamos que la finalidad principal de éstas consistiría en la búsqueda de los niveles que proporcionaron los vasos completos campaniformes, hecho que se comprueba en la propia documentación de Bonsor, pues a partir de ahora denominará El Acebuchal como "estación neolítica" ${ }^{14}$. A ello hay que añadir" el lugar escogido para estas campañas:

“... la parte alta de El Acebuchal donde se encuentran los tres túmulos del grupo central explorados por Peláez y por mí.” (Archivo General de Andalucía, Legado Bonsor: Leg. 4. P. 3. pág. 4).

La información sobre sus trabajos desde fines de Febrero a finales de Mayo que recogemos a continuación se encuentra en la libreta titulada por el propio J. Bonsor "Fouilles archéologiques des Alcores 1908-1912" (manuscrito) (Ibidem) ${ }^{15}$.

Las primeras anotaciones nos informan que se encuentra explorando la zona oeste en dirección al túmulo de "Don Modesto" (fig. 1 b: letra B \{L\}). Debido a la ausencia de hallazgos, resuelve cambiar de lugar y se dirige a la parte central del yacimiento. Allí localiza una treintena de piedras talladas y fragmentos cerámicos, algunos con "dibujos (neolíticos o de transición)". A renglón seguido, realiza unos dibujos con sus correspondientes especificaciones: "un punzón de cobre, una tableta de hueso o marfil y un hacha de piedra pulimentada." ${ }^{16}$ (Archivo General de Andalucía, Legado Bonsor: Leg. 4, P. 3, pág. 7).

Varios días después descubre vestigios de hogares constituidos por una tierra negruzca con cenizas, piedras quemadas, huesos de animales y fragmentos de cerámica, algunos con dibujos geométricos. Este hogar se encontraba bajo uno de los túmulos de incineración aunque sin especificar cuál de ellos (Ibidem, pág. 9).

No fue muy fructífera esta campaña para Bonsor, lo que explicaría su finalización en estos momentos, o bien la atracción hacia otros lugares como Mairena, Carmona y Ranilla, en los que sabemos lleva a cabo exploraciones (Peñalver 1960: 169, recogido en Maier 1988: 150)

Un año después, el 24 de Mayo de 1909, Bonsor reanuda las excavaciones en El Acebuchal, pero la noticia la recogemos de otro de sus diarios (Archivo General de Andalucía, Legado Bonsor: Legajo 15. P. 4). Comienza los trabajos en la zona alta de Los Alcores, en el lugar de los túmulos centrales.

14. J. Bonsor utiliza este término en las publicaciones del siglo pasado para referirse al período cronológico- cultural que va desde fines de la Edad de Piedra hasta la Edad de Bronce. Después, al introducir la cerámica puntillada con dibujos geométricos y no considerarla como producto celta, utiliza el término Neolítico para referirse a los momentos en los que encuadra los silos situados bajo el túmulo A, y Eneolítico o Edad del Cobre para referirse a los pozos y fondos de cabañas en los que aparece cerámica campaniforme.

15. Nombre de la libreta que hoy se encuentra inventariada como Legajo 4. P. 3 (Archivo General de Andalucía, Legado Bonsor). Ésta incluye además excavaciones en otros yacimientos como El Gandul, Bencarrón, Ranilla, etc.

16. La tableta de hueso o marfil, por el dibujo que presenta, corresponde a una placa casi plana con dos escotaduras a ambos lados en el tercio superior de la misma, hallada también en otros yacimientos andaluces como Papa Uvas, donde se la considera "ídolo" (Martín de la Cruz 1986: 48, fig. 27). 
Allí, a una distancia de $20 \mathrm{~m}$. de los veintidós pozos excavados en 1896, aparecen, a una profundidad de un metro, fondos de cabaña de forma circular con zócalo de piedras y pavimento de tierra batida. Seguidamente dice:

“... en esta tierra, cerca de los muros de piedra, se encuentran escondidas las más bellas piezas de cerámica de decoración geométrica (...)". (Archivo General de Andalucía, Legado Bonsor: Leg. 15. P. 4, pág. 23).

A continuación enumera una serie de hallazgos: un hacha de piedra pulimentada, algunos sílex, una espátula de hueso, dos fragmentos de cerámica puntillada, abundantes huesos de animales y piedras quemadas. Concluye afirmando que por los restos que acaba de enumerar se encuentra en un lugar de hábitat y no en una necrópolis. Reflexión que vuelve a repetir al día siguiente; quizás esta preocupación se deba a considerar extraña la presencia de vasos completos en lugares de habitación, o simplemente, aislar este hallazgo de las otras sepulturas presentes en el yacimiento (nos referimos a las de época neolítica y orientalizante).

La siguiente anotación del yacimiento la encontramos en la página 27 de su diario (Ibidem, Leg. 15. P. 4). A unos $50 \mathrm{~cm}$ de profundidad, desde la superficie, aparece otro fondo de cabaña que presenta una extensión de unos $10 \mathrm{~m}$. de diámetro. El pavimento estaba formado por tierra endurecida y piedras, y entre algunas de estas piedras encuentra "grandes fragmentos de cerámica de tipo geométrico", una placa de pizarra, una piedra de molino, una valva de almeja y huesos de animales. También localiza un fragmento de un objeto indeterminado de cobre pero no cree que pertenezca al mismo período que la cabaña, a la que considera neolítica, sino de una "época de transición". No entendemos bien qué quiere decir Bonsor aquí, pues ya en estos años utiliza este término para la Edad del Cobre, aunque le añade "a la del Bronce", época a la que atribuye la cerámica con decoración geométrica (campaniforme), aunque a veces generalice y la llame neolítica.

Así pues, Bonsor ha localizado hasta el momento cuatro fondos de cabaña, uno que se sitúa en el lugar donde halló los 22 pozos, de forma que éstos se encontraban en su interior; otro bajo el "túmulo J" (fig. 1; lám. I); el tercero se sitúa un poco más al norte, a varios metros de distancia -que corresponde al señalado con la letra " $N$ "- y el cuarto, al señalado con la letra " $O$ ", situado a veinte metros de " $N$ " (fig. 1: b). Todos ofrecieron vasos completos y fragmentos de cerámica tipo campaniforme, indicándonos de nuevo que éstas aparecen debajo del pavimento de las cabañas y cerca de los muros de piedra.

En una hoja aparte de este diario, pero que ha sido introducida en la misma página que analizamos (Ibidem, Leg. 15. P. 4, pág. 27), habla de dos vasos enteros que en 1907 compra a R. Pérez ${ }^{17}$.

Finalmente, Bonsor subraya la inexistencia de vestigios humanos, y considera que:

“... es necesario buscar en los alrededores del yacimiento, las sepulturas del tipo de galería y cúpula, de los habitantes de las cabañas. Sin embargo, los que se sitúan en la zona oeste del yacimiento bajo "los túmulos K y J" depositaban a sus muertos en uno de sus silos como en Campo Real, Carmona.". ${ }^{18}$ (Archivo General de Andalucía, Legado Bonsor: Leg. 15. P. 4, pág. 29).

17. Más tarde los venderá a la Hispanic Society of New York.

18. Ya Bonsor por estas fechas había excavado parte de las sepulturas megalíticas de la necrópolis de El Gandul, que contenía ajuares campaniformes; hecho que le lleva a pensar que también debieron existir en El Acebuchal. Los túmulos $\mathrm{K}$ y J se corresponden con los señalados con las letras A y B en su publicación de "Les colonies...." (Bonsor 1899). 
Tres días después (11 de Junio de 1909) sigue excavando los fondos de cabaña donde aparecen muchos huesos de animales, algunos abiertos para extraerles la médula, operación que Bonsor considera debió realizarse con los punzones metálicos hallados en el suelo de estas cabañas. Cita otros hallazgos como dos conchas que interpreta como cucharas, muchos fragmentos de cerámica, algunas con decoración campaniforme, fragmentos de pesas de telar de arcilla, una lámina y dos puntas de flechas de sílex. (Ibidem, pág. 29 y 30).

El 23 de Junio de 1909 escribe:

“... traen los obreros de El Acebuchal fragmentos de cerámica con dibujos geométricos, un punzón de hueso, algunos huesos de animales y un cráneo humano que creo que pertenece a los neolíticos." (ibidem, Leg. 15. P. 4, pág. 31).

Información poco explícita, por lo que tenemos que acudir a la siguiente anotación realizada seis días después:

"Primero R. I. nos conduce hacia el túmulo J que cubría un emplazamiento de cabaña, pero creo que deben tratarse de restos neolíticos como señalamos bajo el túmulo $\mathrm{K}$. Después de algunas horas de trabajo sin encontrar nada volvimos al lugar del emplazamiento de las cabañas (...)" (Archivo General de Andalucía, Legado Bonsor, Leg. 15. P. 4. pág. 32) ${ }^{19}$.

Posteriormente en la página 33, pero en el mismo día anota:

"He visto que el esqueleto encontrado el día 23 se encontraba introducido en el suelo de una cabaña y debía pertenecer seguramente a esta época. El cráneo es pequeño como uno de los descubiertos en el túmulo $\mathrm{K}$-la sutura está cerrada, puede ser una mujer- se ha continuado levantando en la tierra negruzca numerosos fragmentos de vasos con decoración geométrica, punzones de hueso, osamentas de animales, astas de cérvidos, un hacha de piedra mellada, etc." (Ibidem, pág. 33 y 34).

A continuación realiza un comentario sobre el yacimiento de El Argar que le sirve como paralelo de este enterramiento:

"El Sr. M. Siret ha encontrado esqueletos enterrados bajo el suelo de las habitaciones, en posición encogida. Según Siret: en la época del Bronce los cuerpos están dispuestos en grandes recipientes de cerámica o en cofres de piedra". (Ibidem).

Añade Bonsor el dibujo de un plano de situación de la cabaña en la que localizó la sepultura (fig. 1: b, letra "P") (Ibidem, pág. 34). Como podemos ver, se trata del único enterramiento hallado en el yacimiento de El Acebuchal que podemos atribuir, con cierta seguridad, al horizonte campaniforme. Sobre él hablaremos más tarde para no interrumpir la narración de los diarios de Bonsor.

Con este plano y su descripción finaliza sus anotaciones sobre el yacimiento en este cuaderno, ya que también da por terminadas sus excavaciones durante esta segunda campaña. Desde esta fecha hasta el 11 de Diciembre de 1909, que vuelve a El Acebuchal, se encuentra ocupado realizando exploraciones en El Viso y en el yacimiento de La Dehesa de las Monjas en Carmona (Maier 1988: 151). Para anotar

19. Recordemos que los túmulos $\mathrm{K}$ y $\mathrm{J}$ corresponden a los túmulos $\mathrm{A}$ y $\mathrm{B}$, respectivamente, de "Les colonies....". 
los acontecimientos de esta nueva campaña volverá al diario utilizado en las excavaciones de 1908 (Archivo General de Andalucía, Legado Bonsor: Leg. 4 P. 3. pág. 29).

Sabemos que Bonsor sigue excavando los fondos de cabaña, pues comienza su escrito con una nota recordatoria sobre la necesidad de señalar en un plano los siete u ocho fondos que había hallado. Plano que no presenta, e ignoramos si llegó alguna vez a realizar.

Cita los restos del interior de estos fondos: huesos de animales, fragmentos cerámicos, algunos con motivos geométricos; una sierra, dos punzones y una punta de tipo Palmela de cobre, un fragmento de "creciente" de arcilla, un diente de hoz, un alisador de piedra, un disco con una perforación en el centro, también en piedra; así como un fragmento de reborde de hogar en terracota que se encontró en el centro de una de las cabañas conteniendo gran cantidad de cenizas ${ }^{20}$.

La siguiente anotación corresponde al 25 de Enero de 1910, en la que hace una aclaración sobre la atribución cultural de estos últimos hallazgos situándolos en "época eneolítica" o de la "Edad del Cobre", términos que utiliza por primera vez en sus diarios (Ibidem, Leg. 4. P. 3. pág. 28). Se acompaña de una lista en la que se recogen: cerámica de tipo campaniforme, un fragmento de colador, una pesa de telar y un fragmento de anillo en cobre (Ibidem, Leg. 4. P. 3. pág. 34).

De nuevo abandona Bonsor El Acebuchal para trasladar sus excavaciones a Alcaudete y, posteriormente, a la Dehesa del Gandul (Maier 1988: 151). A su vuelta un año después, 3 de Mayo de 1911, prosigue sus trabajos en la parte alta, donde se encontraban los tres túmulos del grupo central. En la tierra utilizada para la construcción del túmulo aparecen:

“... fragmentos cerámicos eneolíticos, huesos de animales, un vaso en forma de tulipa, con el bordecuello fracturado, las paredes lisas; contenía tierra amarilla clara. Una gran olla rayada, encontrada sobre el suelo, contenía tierra y huesos de animales. Dos fragmentos de piedras planas para moler grano. Fragmentos de decoración puntillada". (Archivo General de Andalucía, Legado Bonsor, Leg. 4. P. 3. pág. 4 final).

Finaliza la página con una nota de conclusión:

"Sobre la altura de Los Alcores mirando a la llanura se encuentra un grupo de túmulos de la Primera Edad del Hierro; también túmulos con sepulturas de inhumación de la Primera Edad del Hierro. Bajo estos túmulos aparecen los fondos de cabaña Eneolíticos, de un poblado de la Edad del Cobre. Falta la Edad de Bronce; en esta época los habitantes descienden hacia la llanura. Es preciso buscar sus lugares de habitación y sus sepulturas. (Ibidem, Leg. 4. P. 3. pág. 4 final).

Al día siguiente Bonsor comienza a explorar, debajo del talud del Alcor en una de las terrazas que comunican con La Vega, algunos vestigios de cabañas de la Edad del Hierro. De todas formas, no abandona sus actuaciones en los túmulos del "grupo central", pues seguidamente realiza una enumeración de hallazgos de este lugar: grandes vasijas decoradas en la parte superior del borde y un fragmento decorado con digitaciones o pellizcos, distribuidos de forma desigual por la superficie del vaso ${ }^{21}$, un fragmento de campaniforme de tipo marítimo, del que realiza un dibujo, y un hacha de piedra que encuentra en uno de los fondos de cabaña pero sin especificar cuál (Ibidem, Leg. 4. P. 3. pág. 5 final).

20. La noticia la recoge también en su obra impresa de 1924 (?).

21. Este fragmento presenta la misma decoración que el publicado por Harrison y otros (1976: 14, fig. 25). 
Las siguientes anotaciones aparecen en la página 7 final del diario (sic) y corresponden a trabajos realizados del 8 al 11 de Mayo de 1911 en el túmulo de "El Molino" y en sus alrededores. En la tierra del túmulo aparecen un punzón de cobre y fragmentos de "cerámica eneolítica". También, entre el segundo y tercer túmulo del "grupo central", descubre una abertura rectangular y un silo. En este último Bonsor cita el hallazgo de fragmentos de cerámica, algunas con decoración campaniforme, y huesos de animales.

Varios días después (18 de Mayo de 1911) localiza dos nuevos silos (Archivo General de Andalucía, Legado Bonsor 1. 2., 41. 40) “... situados entre el segundo y el vallado del olivar y el arrecife del alcor, por el lado de la llanura (...)” (Archivo General de Andalucía, Legado Bonsor, Leg. 4 P. 3 , pág 7). Uno no contenía nada; el otro presentaba numerosos fragmentos de platos neolíticos, huesos de animales y un probable "creciente" de terracota, diferente a los ya descubiertos pues es casi plano en lugar de redondeado.

Finalmente, las últimas anotaciones en los diarios de Bonsor sobre El Acebuchal son bastante escuetas; se limitan a enumerar algunos hallazgos como fragmentos de cerámica y una punta metálica. Así, el día 3 de junio de 1911 da por finalizada la excavación de este yacimiento.

\section{RECAPITULACIÓN DE LAS ESTRUCTURAS EXISTENTES EN EL YACIMIENTO}

\section{Los silos}

Bajo el túmulo A (denominado " $K$ " en sus diarios), Bonsor halló cuatro silos comunicados entre sí (fig. 1: a), de los cuales el "D" contenía restos de al menos siete individuos. El desorden de los huesos y la falta de muchas partes del cuerpo le llevan a considerarlo enterramiento secundario u osario (Archivo General de Andalucía, Legado Bonsor: Leg. 12. P. 1. Hoja 4; Bonsor, 1899: 31-33 y 129-130).

El proceso de construcción y posterior utilización de estos silos consistiría en la abertura en la roca de orificios de forma más o menos circular, ensanchándose a medida que se acercaban al fondo, como se aprecia en el plano de "Les Colonies..." (Bonsor 1899: fig. 34) y mucho mejor en el original que se encuentra depositado en el Archivo General de Andalucía (Legado Bonsor 1. 2. 41. 11). En el corte transversal que dibuja del túmulo con los silos se observan de arriba a abajo la capa de tierra externa del túmulo y un nivel de piedras sueltas que descansa sobre el suelo actual donde finaliza el montículo. Un tercer nivel aparece cortado al realizar la fosa de incineración y ocupa la parte superior de las bocas de los silos "A" y " $D$ ". La fosa se encuentra rellena de tres niveles: uno de tierra suelta, otro de fragmentos de ánforas y por último el que contiene las cenizas. A continuación aparecen las bocas de los silos. En ellos también se aprecian distintos niveles. Según Bonsor, el primero contenía tierra suelta con fragmentos de fuentes carenadas muy planas, restos de cerámica muy tosca, junto con pequeños huesos de pájaro, y piedras quemadas. El segundo nivel, formado por una tierra compacta muy dura, presentaba restos humanos. En el silo A aparecieron dos falanges y una vértebra en el fondo, sobre la roca, muy cerca del pasillo de comunicación con el silo "D"; en este último Bonsor llegó a distinguir dos etapas de deposición, una -la primera en llevarse a cabo- contenía restos de al menos cinco individuos con un ajuar compuesto por láminas de sílex y "vasos de cerámicas para contener líquidos" (Archivo General de Andalucía, Legado Bonsor: Leg. 12. P. 1 Hoja 4). Este estrato quedaba sellado por una capa de tierra estéril sobre la que se depositaron dos nuevas sepulturas. 
Bonsor recalca que ni en ellos ni en sus alrededores se halló ningún objeto metálico ${ }^{22}$, al mismo tiempo que los atribuye a época neolítica en todos sus documentos (Ibidem; Bonsor 1899: 31-33 y 129-30). Tampoco existe ningún indicio claro que podamos atribuir a restos de hábitat de época campaniforme, aunque Harrison y otros (1976: 82-83) opinen lo contrario. Este hecho ya ha sido indicado por otros investigadores (Amores, 1982: 69; Serna, 1989: 52) y lo hemos comprobado en las anotaciones inéditas de Bonsor (Archivo General de Andalucía, Legado Bonsor: Leg. 12. P. 1. Hoja 4).

Existen otras referencias de Bonsor a estructuras siliformes en el yacimiento, e incluso comienza llamando así a los primeros pozos que localiza (los denominados más tarde "pozos M") (Ibidem, Hoja 1). Entre el 11 y 16 de Mayo de 1911 excava dos silos en el espacio existente entre los túmulos "H" e "I" (fig. 2 a: $1^{\circ}$ y $2^{\circ}$ ); ambos contenían restos atribuibles al horizonte campaniforme gracias a la presencia en su interior de vasos característicos (Archivo General de Andalucía, Legado Bonsor: Leg. 4. P. 3. Pág. 7 y 8 finales). Dos días después localiza dos silos más que se sitúan al borde del Alcor, al sureste del túmulo H (Fig 2 a: $3^{\circ}$ y $4^{\circ}$ ). Uno se hallaba vacío, mientras que el otro proporcionó abundantes restos cerámicos, que correspondían fundamentalmente a fuentes carenadas, huesos de animales, y un "creciente" de arcilla de sección plana (Ibidem, pág. 12). Este último silo, sin embargo, parece tener mayor relación con los hallados bajo el túmulo A por los materiales descritos.

Las estructuras siliformes son uno de los elementos más característicos de los poblados calcolíticos en Andalucía Occidental. Su conocimiento comienza a generalizarse a mediados de los años sesenta, y llevaría a algunos investigadores a denominar a esta etapa "Cultura de los silos" (Collantes de Terán 1969: 61; Carriazo 1974: 154; Carrilero y otros, 1982). Hoy en día son muy numerosos los yacimientos conocidos que presentan tales estructuras: Papa Uvas, Valencina de la Concepción, Campo Real, Pago de Cantarranas, Las Viñas, Gilena, Marinaleda, Morales y un largo etc. Nos parece más importante destacar que gracias a los datos proporcionados por estos yacimientos, ya no podemos atribuir solamente la presencia de estos silos a una etapa o momento concreto de tránsito Neolítico-Calcolítico, pues la amplitud cronológica que presentan los materiales arqueológicos hallados en ellos indica una utilización durante todo el Calcolítico, incluso en sus momentos finales como el Horizonte campaniforme -independientemente de que su función varíe a lo largo del tiempo- como se ha podido comprobar en Marinaleda (Cruz-Auñón y otros 1992: 378) y en los silos $1^{\circ}$ y $2^{\circ}$ de El Acebuchal.

La variabilidad funcional creemos que es un factor a tener en cuenta, por la importancia que representa en el proceso económico y social de estas comunidades. Consideramos que el término "silo" sólo se debe utilizar para aquellas estructuras destinadas al almacenaje de cereal y/o plantas forrajeras. De esta forma evitaremos equívocos y conclusiones erróneas sobre la importancia de la agricultura en estas comunidades como ya han señalado algunos autores (Lizcano y otros 1991: 278).

\section{Los pozos}

Respecto a los veintidós pozos localizados en las excavaciones de 1896 cerca del túmulo $\mathrm{H}$ (fíg. 1: a) (Archivo General de Andalucía, Legado Bonsor: Leg. 12. P. 1. Hojas: 1, 2, 6, 8, 9 y 9 bis), corresponden a estructuras que aparecen con cierta frecuencia en los poblados de La Edad del Cobre, pero que a veces resulta difícil saber cuál fue su verdadera utilidad, pues al igual que los silos su funcionalidad es múltiple y puede variar a lo largo del tiempo. Así, pudieron servir para guardar cereales u otros alimentos, servir

22. A excepción de un fragmento informe de hierro que correspondería seguramente al ajuar de la sepultura de época orientalizante que se superponía a estos silos. 
de drenaje de otros silos o pozos, basureros o escombreras, lugar de enterramiento, e incluso, pozos de ofrendas en relación con una necrópolis o lugar de culto. Bonsor atribuye esta última función a los hallados en El Acebuchal (Bonsor 1899: 95). Es difícil determinar aquí su verdadera funcionalidad por la parquedad del registro ${ }^{23}$. Sabemos que al menos en los siete que nos describe Bonsor aparecían varios niveles de relleno donde fueron depositándose elementos como, botones de marfil, ídolos, grandes fragmentos de vasos, cazuelas y fuentes con decoración campaniforme, algunas completas, otras lisas; determinadas partes de osamentas de animales como pezuñas y astas de ciervo, partes del cráneo y mandíbulas de cerdos o jabalíes. También un "diente de hoz" y tres pesas de telar. E incluso la presencia de objetos metálicos: puntas de tipo Palmela, cinceles o leznas, un fragmento de sierra y un elevado número de punzones. Objetos que si bien en su mayoría pueden ser considerados elementos de consumo y producción, su presencia conjunta en el interior de estas estructuras no parece tener mucho sentido, si las interpretamos como lugar de almacenaje, basurero o incluso de escondrijo. Otro hecho a tener en cuenta, y creemos que más importante, es que la mayoría de estos pozos de El Acebuchal contienen más o menos unos elementos comunes: una o varias vasijas, decoradas o no, punzones de hueso o metal, restos específicoś de osamentas de animales que parecen coincidir con las partes menos o no comestibles y que se encuentran quemados. El resto de los objetos, sin embargo, los individualiza.

Por otra parte, parece que hubo un interés en cerrar estas estructuras, pues varias de ellas aparecían cubiertas por una capa de piedras (Bonsor 1899: 88), e incluso a algunas se les colocaría una tapadera, realizada con algún material deleznable, que encajaba en la oquedad que se aprecia en ellas (fig. 2 a).

Las dimensiones de estos pozos oscilaban entre 0,75 y $0,60 \mathrm{~m}$ de diámetro en la parte superior o boca, y de 1,20 a $1,10 \mathrm{~m}$. en la base, mientras que la profundidad de 2,20 a $0,70 \mathrm{~m}$., con una distancia de separación entre ellos de no más de $1 \mathrm{~m}$; medidas que no apoyan la atribución de fondos de cabaña a estas estructuras como quiere Berdichewscky (1964: 158). Además, como ya comentamos, Bonsor afirmaba que estos pozos se hallaban en el interior de una gran cabaña (Archivo General de Andalucía, Legado Bonsor: Leg. 15. P. 4, págs. 28 y 35) ${ }^{24}$. Si admitimos tal afirmación, es importante valorar la aparición conjunta de estas estructuras en el interior de una sola cabaña de gran dimensión (10 m. de diámetro), pues la funcionalidad de ésta estaría en estrecha relación con aquéllas. Bonsor en el nivel que ocupaba la cabaña recogió piedras quemadas, huesos de animales y algunos fragmentos cerámicos lisos y con decoración campaniforme. Elementos poco definitorios sobre la posible funcionalidad del recinto, y aunque la presencia de tal concentración de pozos en una misma cabaña pueda inducirnos a pensar en estructuras bien de "redistribución" o bien de "tributo" (Manzanilla 1983: 5-7), tampoco podemos descartar una funcionalidad de tipo ideológico. A todo ello hay que añadir que esta zona del yacimiento debió de ser afectada al construirse los túmulos de época orientalizante, muy próximos a esta cabaña que incluía los denominados pozos "M" ${ }^{25}$.

Por otra parte, los restos arqueológicos que contenían estos pozos, sea cual sea su función, corresponden al Horizonte Campaniforme y, por lo tanto, son coetáneos de los fondos de cabañas localizados encima y en sus inmediaciones.

23. Tenemos que tener en cuenta que Bonsor no señala la existencia de esta cabaña hasta que localiza y excava otros fondos de cabaña en sus inmediaciones, cuya razón se debe a que la mayoría de estos pozos "M" no fueron excavados por él sino por R. Pérez (Archivo General de Andalucía, Legado Bonsor: Leg. 15. P. 4, pág. 27).

24. Ver nota 23.

25. Ya en los primeros trabajos de excavación realizados por Peláez se localizaron materiales del horizonte campaniforme en la tierra de construcción de estos túmulos de época orientalizante (Cabrera 1893; Fernández Casanova 1893; Cañal 1894; Candau 1894 y Bonsor 1899). 


\section{FONDOS DE CABAÑAS O VESTIGIOS DE HÁBITATS}

Nos queda por concretar las noticias sobre estructuras de habitación en El Acebuchal. Respecto al poblado al que corresponderían los enterramientos en silos bajo el túmulo A, las citadas depresiones naturales con restos óseos de animales, sílex, vestigios de hogares, e incluso la presencia de dos molinos (Bonsor 1899: 31) podríamos interpretarlas como fondos de cabañas del poblado correspondiente a los allí sepultados ${ }^{26}$, pero no tienen por qué atribuirse obligatoriamente a lugares de habitación; tampoco a los silos $\left(3^{\circ}\right.$ y $4^{\circ}$, fig. 1 a) podemos asignarles tal función de forma inequívoca, ya que ambos pueden estar relacionados con actividades de la necrópolis próxima. Quizás el nivel hallado por Bonsor en la parte baja del yacimiento, bajo la denominada "roca de los sacrificios", podría pertenecer al poblado de estos momentos. Pero la presencia aquí de platos de borde engrosado y objetos metálicos, nos llevaría a retrasar la fecha de los enterramientos en silos, o a no vincularlo con esta necrópolis.

En lo que respecta al nivel de hábitat de época campaniforme, el área que ocupaba es reseñada por Bonsor en su obra "Les Colonies..." (1899: 88 y fig. 3); sin embargo, la localización y excavación de las cabañas corresponde a sus trabajos de 1908-1911 (Legajo 4. P. 3. Págs. 4-6, 9, 29, 4-11 finales; Legajo 15. P. 4. Págs. 23-35). Según sus propias palabras llegó a localizar 7 u 8 emplazamientos de cabañas, pero sólo sitúa en el plano cuatro de ellos (fig. 4: N, O, P, Q). De los tres o cuatro restantes, sabemos que uno se encontraba encima de los veintidós pozos $\mathbf{M}$; los demás quizás bajo y en los alrededores de los túmulos centrales de época orientalizante.

La planta de estas cabañas era más o menos circular con pavimento de tierra batida en las denominadas "O", "P" y "Q", y de piedras mezclado con arcilla en "N". Sobre las dimensiones de las chozas sólo conocemos la extensión de una de ellas -la cabaña que cubría los "Pozos M"- con $10 \mathrm{~m}$. de diámetro (Legajo 15. P. 4. Pág. 27). Algunas tenían hogares realizados bien con simples piedras o mediante un anillo, de forma de media caña, realizado con barro endurecido al fuego (Ibidem, pág. 28).

La cabaña "O" que tenía un zócalo de piedra ${ }^{27}$, fue la que proporcionó vasos campaniformes completos y, según Bonsor, se hallaban "escondidos" bajo el pavimento en lugares contiguos a los cimientos de piedra (Legajo 15. P. 4. Pág. 23).

También es de destacar la cabaña designada con la letra "P", pues bajo su suelo apareció un enterramiento en posición fetal. La información la recoge en uno de sus diarios (Legajo 15. P. 4. Págs. 32-33) y en las publicaciones de 1924 (?) y 1927. Las primeras noticias (Legajo 15. P. 4. Págs. 32-33), que se refieren al momento del hallazgo, no hacen referencia alguna a la estructura o fosa donde se hallaba el cadáver; tampoco habla de ajuar, quizás debido a su inexistencia que parece ser la tónica general en este tipo de enterramiento (Lull 1983: 147; Escacena y Frutos 1986: 68). En el interior y encima del pavimento donde apareció la sepultura se encontraron fragmentos de cerámica con decoración campaniforme, punzones de hueso, un hacha rota, huesos de animales y astas de cérvidos. En estos primeros momentos, Bonsor no parece tener muy clara la afiliación cultural del allí sepultado, y por ello busca paralelos de este tipo de enterramientos en el Argar. Más tarde, en su trabajo de 1924 (?) hace referencia a esta inhumación pero pluraliza:

“... cavando en el suelo de estas habitaciones se encontraron esqueletos con las rodillas sobre el pecho, que probablemente pertenecían a tiempos anteriores neolíticos.” (Bonsor, 1924 (?): 4).

26. Bonsor en sus escritos no hace referencia alguna al tamaño de estas oquedades naturales, por lo que su utilización como fondos de cabaña es hipotética.

27. Bonsor no menciona este elemento constructivo cuando describe las demás cabañas. 
Sin embargo, en la publicación de 1927 ya no aparece tal atribución sino que la hace corresponder junto con las cabañas y las vasijas allí halladas (con decoración campaniformes) a la Edad del Cobre (Bonsor 1927: 290-291). Quizás en la exploraciones que R. Pérez realizó entre 1897 y 1907, llegó a localizar otros enterramientos bajo las cabañas en la parte alta de El Acebuchal. Sin embargo, poseemos una noticia al respecto, a la que hemos ya hecho alusión, en la que hace referencia también a otro asentamiento con fondos de cabaña, al otro lado del Puerto de El Acebuchal, cerca de la "Casilla del Cura" (Legajo 18. P. 9. Pág. 39) (fig. 2: b).

La presencia de enterramientos bajo las viviendas o en el interior de los poblados en el Bajo Guadalquivir es un hecho constatado a partir de las excavaciones de los yacimientos de Monte Berrueco (Escacena y Frutos, 1981-82, y 1986: 67-69) y Setefilla (Aubet y Serna, 1981). Así este hallazgo de El Acebuchal junto con el de Amarguillo II (Molares, Sevilla) (Cabrero 1986 y 1987) son las primeras muestras de la utilización de este nuevo sistema de enterramiento, que pasará a formar parte de la ya variada tradición funeraria de estos momentos: sepulturas en fosa, cistas, cuevas artificiales y reutilización de construcciones megalíticas.

Como hemos podido comprobar, son muchas las estructuras existentes en este asentamiento que corresponden a lo que se denomina época calcolítica. El yacimiento se encuentra ubicado en un área de excelentes posibilidades agrícolas (Vega del río Corbones), actividad económica atestiguada por su cultura material (dientes de hoz, hachas y azuelas pulimentadas, molinos, moletas y silos), pero acompañada de una también importante cabaña doméstica (bóvidos y cerdos), junto con actividades cinegéticas llevadas a cabo en los bosques cercanos (jabalíes, ciervos, etc.). También existen en el yacimiento pruebas de actividades diversificadas: de proceso metalúrgico (restos de escorias, mineral y crisoles), textil (pesas de telar y fusayolas), alfareras, así como, elementos de "lujo" o "prestigio" fruto de intercambio (marfil, conchas, cinabrio, etc.)

Sus pobladores aprovechan el reborde del Alcor -zona no fértil- para situar su lugar de hábitat y necrópolis, al mismo tiempo que le permite una buena visibilidad. Existe una concepción de espacio único por parte de estas comunidades en las que se mezcla el espacio doméstico y el funerario.

Hasta aquí la recapitulación sobre la información de las estructuras existentes en el yacimiento de El Acebuchal obtenida de los Diarios y anotaciones inéditas de Bonsor y de las publicaciones contemporáneas y posteriores al autor. La documentación que hemos consultado de los fondos de Bonsor en el Archivo General de Andalucía ha estado mediatizada por la búsqueda de aquellos datos imprescindibles para la elaboración del presente trabajo ${ }^{28}$; no obstante, hemos podido comprobar que la información allí conservada es muy amplia y de gran interés para todo investigador de la arqueología andaluza, por lo que animamos a su consulta.

28. Sobre los aspectos inéditos de época orientalizante hallados por Bonsor en este yacimiento realizamos una comunicación en el Congreso de Estudios Fenicios celebrado en Cádiz en Octubre de 1995 (en prensa). Igualmente, tenemos en preparación un artículo en el que se incluye el estudio de todos los objetos arqueológicos localizados en las estructuras calcolíticas descritas en el presente trabajo. 


\section{BIBLIOGRAFÍA}

AUBET, M ${ }^{a}$ E. y SERNA, Ma R. (1981): "Una sepultura de la Edad del Bronce en Setefilla" Trabajos de Prehistoria 38, 225-251.

BERDICHEWSCKY, B. (1964): Los enterramientos en cuevas artificiales del Bronce I hispánico. Bibliotheca Praehistórica Hispana, vol. VI. Madrid.

BONSOR, J. (1885): "El túmulo de Alcaudete". Memoria de la Sociedad Arqueológica de Carmona. _- (1897): "Notas arqueológicas de Carmona". Revista de Archivos, Biblioteca y Museos. T. I: 568-570.

_ (1899): "Les colonies agricoles pré-romaines de la vallée du Bétis". Revue Archéologique, XXXV. Paris

_ (1924 (?)) S/l. S/c. S/e. "El origen verdadero de Carmona".

_ (1927): "La véritable origine de Carmona et les découvertes archéologiques des Alcores". Revue Archéologique, $5^{\mathrm{a}}$ Serie. Paris.

BOSCH, P. (1940): "The types and chronology of West European Beakers", MAN, XL, $\mathrm{n}^{\circ} \cdot 1-2$.

- (1962): "L' expansion du vase campaniforme". Munera Archeologica Iosepho Kostrzewski, pp. 103-116. Poznan.

CABRERA, A. (1893): "Una excursión a los yacimientos prehistóricos de Carmona". Anales de la Sociedad de Historia Natural, vol. XXIII: 101-115 y Lám. I-IV.

CABRERO, R. (1986): "Informe preliminar sobre las excavaciones arqueológicas realizadas en el yacimiento de Amarguillo II (Los Molares, Sevilla)" Anuario Arqueológico de Andalucía, II: 180-185. (1987): "El poblado de la Edad del Cobre denominado Amarguillo II (Los Molares, Sevilla). Informe preliminar de la excavación sistemática de 1987". Anuario Arqueológico de Andalucía, II, pp. 276-277. CANDAU, F. (1894): Prehistoria de la provincia de Sevilla. Sevilla.

CAÑAL, C. (1894): Sevilla Prehistórica. Sevilla.

- (1897): "Nuevas exploraciones de yacimientos prehistóricos en la provincia de Sevilla". Anales de la Sociedad Española de Historia Natural, Vol. XXV: 351-374.

CARRIAZO, J. de M. (1974): Protohistoria de Sevilla. Sevilla.

CARRILERO, M. y otros (1982): "El yacimiento de Morales (Castro del Río, Córdoba). La cultura de los silos en Andalucía Occidental". Cuadernos de Prehistoria de la Universidad de Granada, 7: 171-205.

CASTILLO, A (1922): "La cerámica incisa de la Cultura de las Cuevas de la Península Ibérica y el problema del origen del vaso campaniforme” Anuario de la Universidad de Barcelona, pp. 1- 20, láms. I-VI. Barcelona.

- (1928): La cultura del vaso campaniforme. Su origen y extensión en Europa. Barcelona.

(1943): "Cronología de la cultura del vaso campaniforme en la P. Ibérica", Archivo Español de Arqueología, XVI, pp. 388-435. Madrid.

_ (1955): "La vida y obra de J. Bonsor y la arqueología de su tiempo". Revista de Archivos, Biblioteca, y Museos: LXI: 615-635.

COLLANTES DE TERÁN, M. (1969): "EL Dólmen de Matarrubilla" $V^{o}$ Symposium de Prehistoria Peninsular: 47-62. Barcelona.

CRUCES, E. (Dtra) (1991): Inventario del Archivo y Biblioteca de Jorge Bonsor. Archivo General de Andalucía. Consejería de Cultura y Medio Ambiente. Junta de Andalucía. Sevilla.

CRUZ-AUÑón, R. y otros (1992): "Proyecto: Estudio del hábitat Calcolítico en el pie de Sierra del Bajo Valle del Guadalquivir”. PROYECTOS 1985- 1992: 373-382. 
ESCACENA, J. L. y FRUTOS, G. (1981-82): "Enterramientos de la Edad del Bronce del Cerro del Berrueco (Medina Sidonia, Cádiz)" Pyrenae 17-18: 165-189.

(1986): "El Tránsito del Calcolítico al Bronce a través del "Monte Berrueco" de Medina Sidonia (Cádiz)", Trabajos de Prehistoria, 43: 61-84.

FERNÁNDEZ CASANOVA, A. (1893): "Necrópolis prehistórica de Carmona". Boletín de la Real Academia de Bellas Artes de San Fernando. Año XIII, nº130: 306-320.

FROTHINGHAN, A. W. (1953): Prehistoric pottery in the collection from El Acebuchal, site near Carmona, province of Sevilla. The Hispanic Society of America, New York.

HARRISON, R. J. (1977): The Bell Beakers cultures of Spain and Portugal. Havard University.

- (1980): The Beaker Folk. Cooper Age Archaeology in weistern Europe. Thames \& Hudson, London.

HARRISON, R. J. y otros (1976): "The beaker pottery from El Acebuchal. Carmona (prov. Sevilla)". Madrider Mitteilungen, 17: 79-141.

LIZCANO, R. y otros (1991): "1 $1^{a}$ Campaña de excavaciones de urgencia en el Pabellón Polideportivo de Martos (Jaén)" Anuario Arqueológico de Andalucía 1991, III (Actividades de urgencia), pp. 278-291, Cádiz.

LULL, V. (1983): La "Cultura" de El Argar. (Un modelo para el estudio de las formaciones económicosociales prehistóricas). Barcelona.

MAIER, J. (1988): "El epistolario de J. Bonsor. Correspondencia con Luis Siret". Actas del I Congreso Internacional Historiografía de la Arqueología y la Historia Antigua. Siglos XVIII-XX: 149-156.

MANZANILLA, L. (1983): "La redistribución como proceso de centralización de la producción y circulación de bienes. Análisis de dos casos" Boletín de Antropología Americana, n 7, pp. 5-18.

MARTÍNEZ SANTA-OLALLA, J. M. (1947): "Obras maestras hispánicas de la cerámica de estilo campaniforme". Cuadernos de Historia Primitiva, III: 65-94.

MARTÍN DE LA CRUZ, J. C. (1986): "Papa Uvas II". Excavaciones arqueológicas de España, 149.

PEÑALVER, M. (1960): Don Jorge Bonsor: apuntes para una biografía. Memoria de licenciatura, Sevilla. (inédita).

SERNA, M". R. (1989): "El vaso campaniforme en el valle del Guadalquivir, Tartessos, Barcelona: 47-84.

USCATESCU, A. (1992): Los botones de perforación en " $V$ " en la Península Ibérica y Las Baleares durante la Edad de los Metales. Madrid. 

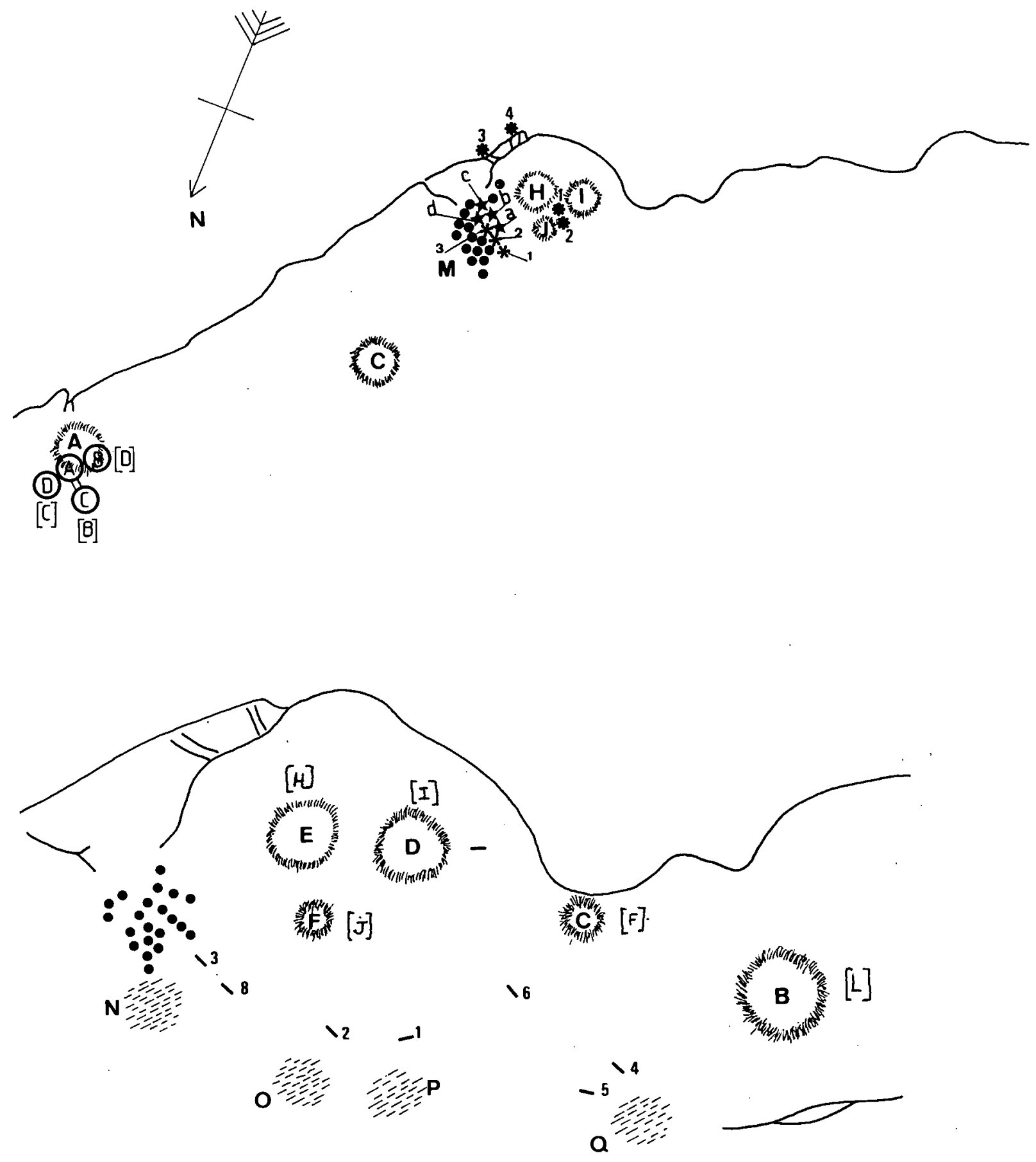

Fig. 1 : a) Plano del yacimiento de El Acebuchal en el que se aprecia la situación de los silos ( (A), (B), (C), (D), *: 1, 2, 3, 4) "pozos M" y algunos de los túmulos (A, C, H, I y J), realizado a partir de varios dibujos inéditos de Bonsor (Archivo General de Andalucía, Legado Bonsor: sección planos y dibujos 41.41 y sección manuscritos: Leg. 12. P 1, hoja 4 y hoja 9 bis). b) Plano de El Acebuchal en el que se observa algunos de los túmulos (H, I, J, F y L) y la disposición de los denomina dos "lapidados" (1-8) correspondientes al periodo orientalizante, junto con los veintidós "pozos M" y la situación de las cabañas de época campaniforme (N, O, P, Q). Obtenido a partir de varios dibujos de Bonsor (Archivo General de Andalucía, Legado Bonsor: sección planos y dibujos 41.41 y sección manuscritos: Leg. 15. P. 4, pág. 34). 

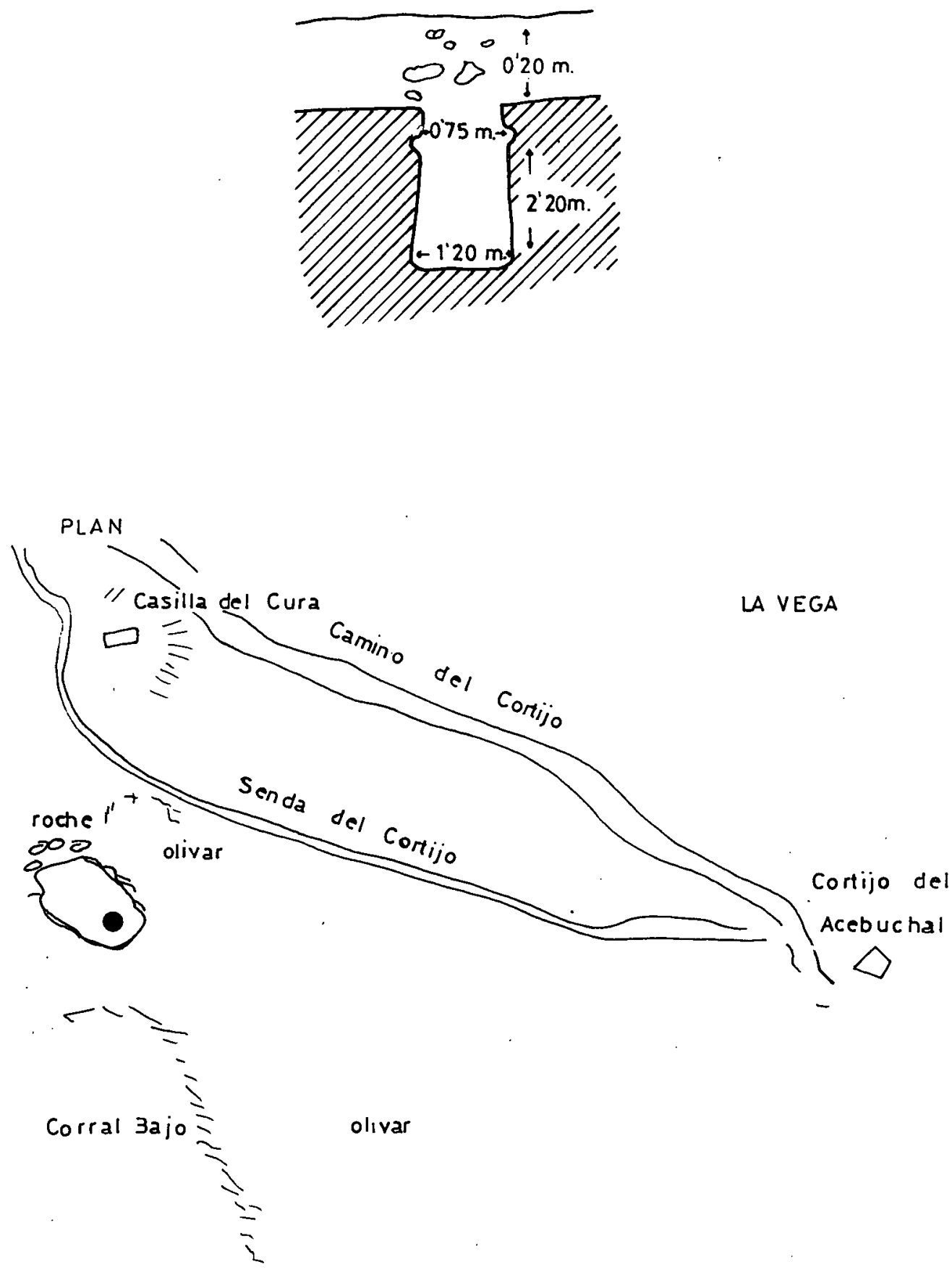

Fig. 2: a) Dibujo de la sección de uno de los veintidós de los denominados pozos "M" realizado por Bonsor (Archivo General de Andalucía, Legado Bonsor: Leg. 12, P. 1, hoja 2). b) Plano de situación del lugar denominado "Casilla del Cura", donde Bonsor localizó algunas estructuras de habitación. Copia del dibujo realizado por Bonsor en uno de sus diarios de excavaciones (Archivo General de Andalucía: Legado Bonsor: Leg. 18, P. 9, pág. 39). 


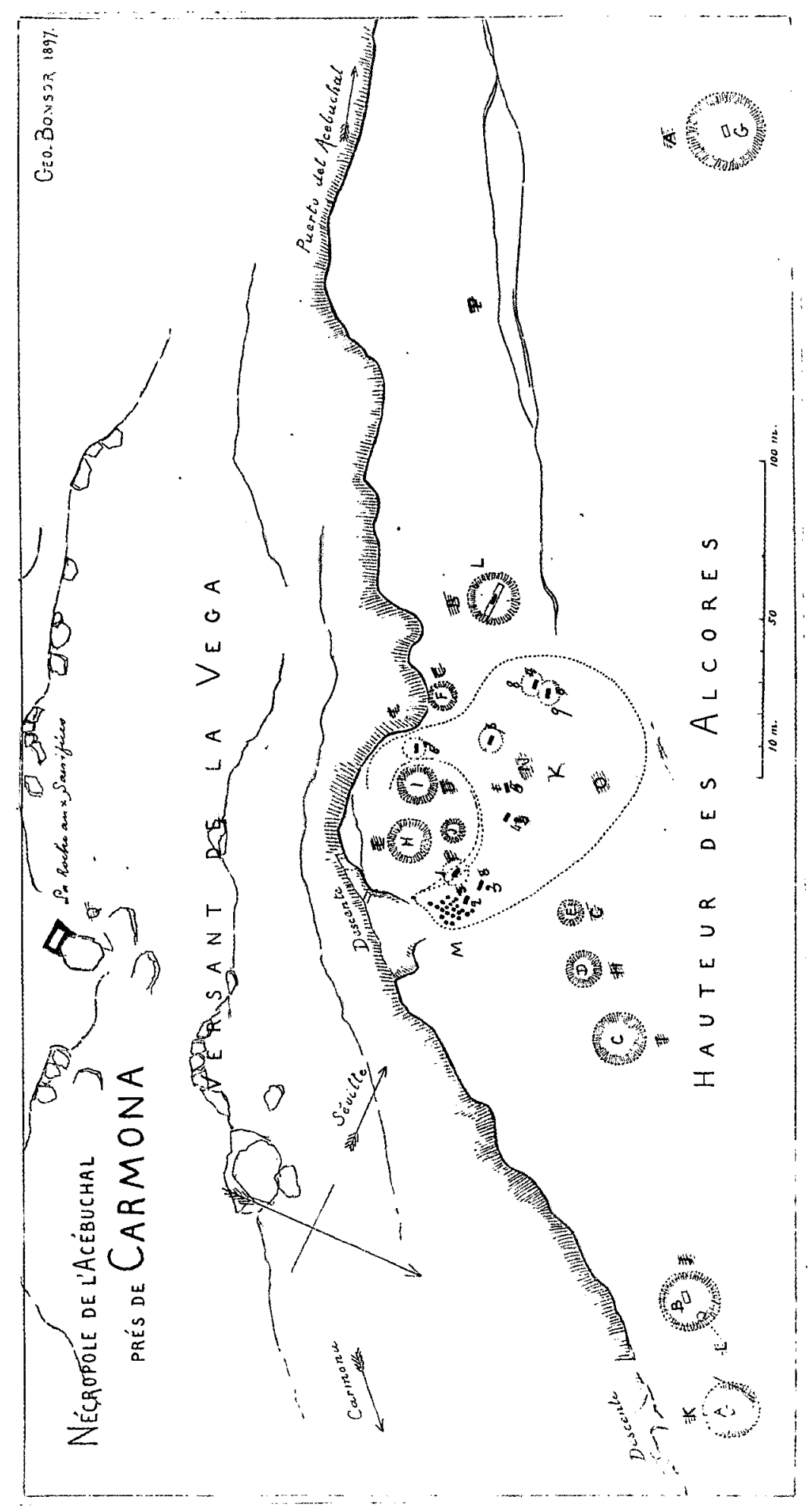

